\title{
Gasto Fiscal y Dólar
} Una relación (1) 1 (1)

\section{Sobre la relación entre el gasto fiscal y el dólar podemos} decir una sola cosa segura, la conexión entre estas dos variables es compleja.

Carlos J. García, Ph.D. en Economía, University of California (LA), EE.UU. Académico FEN-UAH

mpecemos por el modelo Mundell-Fleming, que es enseñado en casi todas las universidades del mundo. Este predice que un aumento del gasto fiscal sube primero la tasa de interés y luego la moneda doméstica se debe depreciar. Una de las claves para entender esta predicción es la existencia de movilidad en los flujos de capitales internacionales. En efecto, un aumento de la tasa de interés en Chile, por ejemplo, produce que sea más rentable depositar dólares acá que en otros países. La mayor oferta de divisas, suponiendo un tipo de cambio flexible, debiera reducir el precio del dólar.

La implicancia de política económica de este último modelo es clara y dramática. La caída del precio del dólar debiera desincentivar las exportaciones y con esto se diluye el impulso inicial de un mayor gasto sobre el PIB. Por el contrario, en una economía con tipo de cambio flexible y movilidad de capitales, la política correcta para estabilizar la economía es la política monetaria, y no la fiscal. ¿Por qué? Bueno, la expansión del PIB se puede lograr bajando la tasa de interés, que sacando capitales de la economía logra depreciar el peso. En efecto, la depreciación del peso, enseguida, incentiva las exportaciones y con esto el crecimiento en el corto plazo o cíclico de la economía.

Siguiendo esta línea de pensamiento muchos economistas aconsejan olvidarse de la política fiscal para estabilizar la economía. La tarea del gobierno por el contrario debe concentrase en promover el crecimiento, asegurando el gasto social en áreas clave como la educación, la salud, seguridad social, etc. La estabilización del ciclo económico es tarea del Banco Central, que a través del manejo de la tasa de interés debe controlar la inflación y reducir la brecha entre el PIB efectivo y el potencial. De hecho, bajo ciertas condiciones, algunos economistas se refieren a esta relación entre inflación y brecha del producto como la "divina" coincidencia. Es decir, la política monetaria, como en una partida de billar, puede controlar la inflación a través de la reducción de la brecha del producto. Espectacular, casi mágico sin duda alguna.
La varita mágica en todo este análisis es una relación empírica que ocasiona lo más acalorados debates entre los economistas de todas las escuelas de pensamiento: la curva de Phillips. Esta es una relación, positiva entre inflación y brecha del producto que se ha encontrado o no en muchos países. Bueno y ¿por qué tanto debate con esta famosa curva además de su extraño nombre? La clave es que la inflación por un aumento de la brecha del producto es menor que en el caso que los precios de la economía hubieran sido completamente flexibles. En otras palabras, está en juego un punto clave para los economistas: si el sistema de precios funciona o no para distribuir los recursos de la economía en el corto plazo (dos años). Para los economistas más apegado a la tradición de escuelas como Chicago, UCLA, Minnesota, y pensadores como Milton Friedman y Robert Lucas entre otros, la curva de Phillips es sin duda una real molestia. Por el contrario, para los economistas más apegado a la tradición keynesiana como Samuelson, Blanchard, Summer, atrincherados en escuelas como MIT, Harvard, Berkley, etc., la curva de Phillips es la clave de toda la estabilización económica. La falla del mercado debe ser resuelta por el Estado, en particular, en una economía abierta con flujo de capitales, por el Banco Central.

\section{"La política monetaria} no es la única forma de estabilizar la economía, pero los efectos de la política fiscal, si bien salvan el día, pueden tener efectos inesperados que complican su uso en el futuro, en especial debilitando más que fortaleciendo el peso"
Sin embargo, la historia no es tan simple entre gasto fiscal y dólar. Primero, la varita mágica, la curva de Phillips, está bajo cuestionamiento, pero no por un aumento de la flexibilidad de precio como soñarían los economistas monetaristas de la tradición de Chicago sino por una estabilización de la inflación a rango bajos y estables. Al parecer, pase lo que pase, la inflación no baja ni sube. En efecto, en plena crisis internacional del 2008 se pronosticó una deflación parecida a la gran depresión. ¡Pero no ocurrió! Luego la Fed y el Banco Central Europeo (ECB en inglés) inundaron los mercados con dólares y euros, y no se produjo inflación. Parece que la divina coincidencia es una ilusión o un fantasma que se pasea sólo en los departamentos de estudio de los bancos centrales y en la mente imaginativa de algunos economistas académicos.

Segundo, a pesar del consejo del modelo de Mundell-Fleming de no usar la política fiscal en un contexto de flujo de capitales y tipo de cambio flexible, los gobiernos, incluido el chileno, usan sistemáticamente política fiscal para estabilizar la economía. Considerando que los ministros de Hacienda en Chile y en muchos países, incluido los Estados Unidos, son economistas competentes, algo de efectividad debe tener la política fiscal a pesar del consejo negativo de Mundell-Fleming. En efecto, cuando un país entra en una crisis o en un ciclo de bajo crecimiento, la política monetaria parece seguir un camino muy largo para ser efectiva. En especial, debe pasar por los bancos privados, quienes en un contexto de mayor incertidumbre no están dispuestos a prestar a cualquier persona y/o empresa. En este escenario, una menor tasa de interés del Banco Central demora en traspasarse a las tasas de los bancos privados y con esto afectar el consumo e inversión privada. Así, no queda otra que perder la compostura, olvidarse de modelos económicos elegantes y gastar más, directamente a través del gobierno para estabilizar la economía. Cómo la revista The Economist explica sobre este punto, si te fallan las balas y las flechas, no te queda más que las piedras y finalmente los mordiscos.

Tercero, y como hemos aprendido, la apreciación del peso por un mayor gasto fiscal también está bajo duda. En efecto, observemos el caso extremo y reciente de Argentina, una política fiscal expansiva no llevó a una apreciación, muy por el contrario, el exceso de deuda fiscal subió a las nubes el riesgo país y con ello el precio del dólar. Esto no es solo el caso de Argentina, también Chile experimentó un efecto en la misma dirección, pero claramente más moderado. Justamente, el exceso de deuda fiscal también subió el riesgo país y en conjunto con otros elementos gatilló la depreciación del peso en las últimas semanas. Entre esos otros elementos debemos considerar importantes hechos como la normalización de la política monetaria en los Estados Unidos, la no tan inteligente guerra comercial entre este país y China, la crisis argentina y turca, etc. $\mathbf{E}$ 